\title{
Perfil e tendências da liderança em uma empresa brasileira líder mundial de mercado
}

\author{
Marco Aurélio de Oliveira ${ }^{a *}$, Osmar Possamai ${ }^{\mathrm{b}}$, Luis Veriano Oliveira Dalla Valentina ${ }^{\mathrm{c}}$ \\ a*mdmaviro15@gmail.com, UFSC, Brasil \\ bpossamai@deps.com.br, UFSC, Brasil \\ 'dalla@joinville.udesc.br, UDESC, Brasil
}

\begin{abstract}
Resumo
0 objetivo deste trabalho é o entendimento de como a liderança ocorre em uma empresa brasileira líder mundial em seu mercado de atuação, em tempos marcados por grandes incertezas, particularmente nos dias atuais. Trata-se de uma pesquisa qualitativa, orientada pelo paradigma interpretativo, que busca, a partir dos dados colhidos em entrevistas com informantes, descrições detalhadas e interpretações para o fenômeno da liderança na organização em estudo. 0 ambiente onde a pesquisa foi desenvolvida é uma área de pesquisa e desenvolvimento de uma empresa brasileira líder mundial no seu mercado de atuação. Os tipos de liderança considerados foram a transacional e a transformacional. No presente trabalho também são discutidos aspectos relacionados com a tendência de evolução e posicionamento dessa liderança em termos de um cenário globalizado.
\end{abstract}

Palavras chave

Estilo de liderança. Comportamento organizacional. Estrutura organizacional.

\section{Introdução}

0 mundo atual cada vez mais é caracterizado por incertezas. Essas incertezas são fruto de mudanças contínuas nos mercados, do advento da globalização e da consequente queda de barreiras e protecionismo que existiam em décadas passadas. 0 mundo atual é marcado por mudanças contínuas e acentuadas. Não existem mais barreiras intransponíveis. 0 mundo ficou pequeno, não existem garantias naturais de sobrevivência. As barreiras geográficas estão sendo derrubadas por soluções logísticas, assim como as de comunicação (vide o advento da internet). 0 mundo dos negócios tornou-se globalizado. As grandes empresas que vivem essa realidade são corporativas, e para tal, devem apresentar estruturas organizacionais flexíveis. A corporação tem de ser ágil para conviver com a concorrência feroz de mercado, antecipar-se em relação à concorrência e para minimizar as ameaças à sua sobrevivência e transformá-las em oportunidades. Paralelamente a essa globalização e à queda de barreiras, surgem também exigências em termos de legislação (normas), desde as mais genéricas, como o apelo a produtos ecologicamente corretos, até algumas mais restritivas e particulares, do ponto de vista de acesso a determinados mercados potencialmente atraentes (ex.: tipo de mão de obra, nível de automação de linhas de produção, parcerias, impostos etc.).

Esse cenário tem levado as organizações a revisarem seus processos, suas estruturas organizacionais, seus produtos e o perfil de seus funcionários. 0 relacionamento com culturas diferentes, com valores diferentes, pessoas com perfis diversos, sejam eles no papel de pares de uma mesma organização, em diferentes países, ou sejam, mesmo, de clientes e a mudança das estruturas organizacionais tornando-se cada vez mais horizontais e matriciais têm influenciado diretamente outro fator, a liderança. A liderança em pessoas torna-se fundamental como pilar de sustentação da liderança tecnológica e de mercado, uma vez que acesso a tecnologia e métodos é feito com o aporte do conhecimento, ação e postura das pessoas. A própria liderança tem se modificado nos últimos tempos em função desse cenário. Segundo 
Ancona (2005), a liderança atual exercida em tempos de incerteza é caracterizada por ser:

- Distribuída, ou seja, ela permeia toda a organização;

- Pessoal e que pode ser desenvolvida, com líderes exercitando suas melhores aptidões no dia a dia e procurando, continuamente, melhorar e desenvolver habilidades;

- Um processo de criação de mudança, de fazer acontecer, criando um ambiente no qual as pessoas estejam energizadas e motivadas para desafios e resultados.

0 objetivo deste trabalho é o entendimento de como a liderança ocorre em uma empresa brasileira líder mundial em seu mercado de atuação, em tempos marcados por grandes incertezas, particularmente nos dias atuais. As perguntas de pesquisa que regem este estudo são:

- Como a liderança é exercida na organização sob a perspectiva de líderes e de liderados?

- Quais são as percepções e experiências de líderes e liderados no seu ambiente de trabalho?

- Quais são as oportunidades de desenvolvimento da liderança na organização?

\section{Referencial teórico}

São adotadas neste estudo as perspectivas sobre liderança de Yukl (2002), considerando as fontes do poder (pessoal e posição), e de Bass (1997), contemplando a liderança transacional e a liderança transformacional.

A liderança transacional está diretamente relacionada ao reforço por contingência. Seguidores são motivados pelas promessas dos líderes e recompensas, ou são corrigidos em seus comportamentos via feedbacks negativos, reprovações, ameaças ou ações disciplinares (Bass \& Steidlmeier, 1998). As formas de gerenciamento de comportamentos neste caso são:

Recompensa contingencial: Líderes devem indicar, ou então consultar seus seguidores sobre o que tem de ser feito em troca de recompensas implícitas ou explícitas;

Gerenciamento ativo por exceção: Líderes monitoram o desempenho dos seguidores e corrigem os erros/enganos desses seguidores;

Gerenciamento passivo por exceção: Líderes esperam passivamente pelos erros/enganos dos seguidores para corrigi-los, via feedbacks negativos ou repreensões;

Laissez-faire: Nesse caso líderes evitam liderar, ou seja, se eximem do papel de líder.

A liderança transacional é focada nas interações entre líderes e seguidores nas quais, através de transações, um indivíduo ganha poder de influência e o sustenta ao longo do tempo. Esse processo é recíproco, ou seja, liderados são recompensados, com o líder ganhando força atendendo às expectativas dos seguidores. Segundo Stone \& Patterson (2005), esse tipo de liderança é especialmente aplicado a situações ou ambientes nos quais se deseja gerenciar a rotina do dia a dia, não necessariamente preocupando-se com o foco no crescimento futuro da organização, como um todo, via a busca de melhor performance dos indivíduos. 0 conceito da liderança transacional é fortemente relacionado com a autoridade burocrática.

A liderança transformacional, por sua vez, busca que seguidores transcendam seus interesses individuais para o bem do grupo, organização, ou sociedade, focando no progresso e desenvolvimento em longo prazo. Ela é alicerçada por quatro componentes básicas:

Carisma ou influência idealizada: Pode ser atribuída ou comportamental - proporciona altos padrões de emulação, gerando visão e confiança;

Motivação inspiracional: Provê desafios e engajamento dos seguidores para com objetivos compartilhados;

Estimulação intelectual: Estimula a formulação de visão, análise crítica e avaliação de situações, implementação de padrões e geração de soluções criativas;

Consideração individualizada: Consiste no tratamento dos seguidores como indivíduos, via seu treinamento, desenvolvimento e orientação, na busca de seu crescimento.

De acordo com Bass (1997), líderes transformacionais transformam valores pessoais dos seguidores para suportar a visão e os objetivos da organização através da criação de um ambiente onde relacionamentos são formados e estabelecendo um clima de confiança onde visões são compartilhadas. Seguidores respeitam e confiam em líderes transformacionais e adaptam seus próprios valores para aqueles dos líderes, dando poder a esses líderes. Nesse conceito, o caráter importa, ele é base da liderança. Kouzes \& Posner (1987) citam vários estudos que indicam que as características mais valorizadas pelos liderados são honestidade, integridade e credibilidade. A credibilidade é vista como parte fundamental e mediadora da verdadeira liderança transformacional. O objetivo maior da liderança é criar uma visão compartilhada de futuro.

Para Yukl (2002), é importante entender que o processo de liderança é baseado na influência sobre os seguidores e que a capacidade do líder de influenciar seguidores é denominada poder. As fontes de poder podem ser o poder pessoal e o poder de posição. 0 
poder de posição inclui a potencial influência gerada a partir da autoridade legitimada e de controle sobre recursos, recompensas, punições, informação e sobre o ambiente físico do local de trabalho. Já o poder pessoal está atrelado com a potencial influência derivada da capacitação para a tarefa (expertise) e a potencial influência a partir da amizade e lealdade (poder de referência). Estudos mostram que tanto o poder do expertise como o de referência estão bem correlacionados a satisfação, comprometimento e melhor performance dos seguidores. Politis (2003) mostra que o poder de referência e o poder do expertise são fatores determinantes da comunicação, do entendimento de problemas e da organização e que o poder de referência facilita a negociação com e entre seguidores. Quando um líder propõe mudanças bem-sucedidas, ganha a confiança do grupo, adquire maior credibilidade e seu nível de influência aumenta. Por outro lado se o líder demonstra ser egoísta ao invés de leal para com o grupo, ele cai em descrédito. Isso afeta a legitimidade do líder por parte de sua equipe de trabalho (Menegasso \& Salm, 2005).

As perspectivas de Yukl e Bass podem ser correlacionadas ao fator credibilidade do líder. Nas formas de aumentar o poder pessoal do líder e obter credibilidade sugeridas por Yukl (2002) estão inseridos os componentes da liderança transformacional de Bass (1997). No que diz respeito ao poder do expertise, percebe-se a presença do carisma ou da influência idealizada, proporcionando e gerando padrões de emulação, visão e confiança. Da mesma forma podem ser associadas também a motivação inspiracional e a estimulação intelectual. 0 líder busca mais conhecimento, mantem-se informado, desenvolve fontes de informação, é competente na solução de problemas, tornando-se mais preciso e assertivo e servindo de exemplo para a equipe. A consideração individualizada está inserida no poder de referência, onde fica evidenciada a questão da preocupação com a satisfação, o bem-estar, o crescimento dos seguidores e sua orientação, a manutenção e o cumprimento de promessas. Para Yukl (2002), uma das principais razões de seguidores serem motivados por líderes transformacionais a desempenharem além das expectativas é a crença e o respeito que esses seguidores têm por seus líderes. Líderes transformacionais criam uma visão de forma clara e convincente e explicam como atingir essa visão. Eles são confidentes e otimistas, acreditam nos seus seguidores, enfatizam valores e valorizam ações, lideram pelo exemplo e potencializam suas equipes para atingirem a visão.

Na visão de Heifetz (1994) e Northouse (2004), a liderança transformacional também pode ser considerada liderança adaptativa, uma vez que existe a mobilização de grupos de pessoas para vencerem desafios e atingirem uma visão. Líderes têm de entender a importância do conceito de adaptação e serem hábeis na mudança de processos organizacionais e na escolha de ferramentas adequadas para a melhoria da organização. 0 termo adaptativo vem da teoria da adaptação das espécies da biologia evolucionária. Organizações se desenvolvem através da mudança do meio e da implementação de objetivos e visões estratégicas. As competências necessárias para que isso aconteça são as mesmas encontradas na descrição dos componentes da liderança transformacional.

\section{Método}

Trata-se de uma pesquisa qualitativa, orientada pelo paradigma interpretativo (Morgan, 1980) que busca, a partir dos dados colhidos em entrevistas com informantes, descrições detalhadas e interpretações para o fenômeno da liderança na organização em estudo. As etapas de estruturação das entrevistas foram as seguintes:

- Negociação com representantes da empresa e da área para realização da pesquisa; primeiramente foi feito um contato com o gestor da área de P\&D da empresa, oportunidade em que foi feita a descrição do projeto e de todas as suas etapas constituintes;

- Garantia de sigilo das informações e da não identificação dos informantes, via o estabelecimento de um contrato individual de confidencialidade entre os participantes do processo, visando proteção dos informantes;

- Entrevistas individuais, agendadas previamente, com consulta aos informantes e conversa preliminar individual, convidando-os a participar da pesquisa, e posterior agendamento prévio das entrevistas seguintes;

- Validação da metodologia e do roteiro das entrevistas através da realização de entrevistas piloto, com a realização de duas entrevistas piloto com integrantes da área onde a pesquisa foi conduzida, com o objetivo de validação da metodologia e do roteiro das entrevistas;

- Armazenamento das informações através da definição de formas de salvaguarda e acesso restrito aos dados e informações obtidos a partir das entrevistas.

As entrevistas foram estruturadas em questões de pesquisa e questões auxiliares respectivas, associadas a cada uma delas. 0 objetivo dessas questões auxiliares foi servirem como roteiro para a entrevista e como ajuda na coleta de dados e informações relevantes (Spradley, 1979, 1980). As questões de pesquisa e as respectivas questões auxiliares foram as seguintes: 
a) Como a liderança é exercida na organização e percebida por líderes e liderados?

a.1) Existe algum tipo de pessoa, em especial, que se torna líder?

a.2) Quais são as qualidades que tornam um líder efetivo e competente?

a.3) Você se vê (percebe) como líder?

a.4) Líderes são feitos ou são natos?

a.5) Você gostaria de fazer algum comentário adicional?

b) Quais são as percepções e experiências, de líderes e liderados, no seu ambiente de trabalho?

b.1) Quem (quais pessoas) exerce $(m)$ a maior influência no seu trabalho?

b.2) Como você descreve essa influência?

b.3) Como é exercida a liderança nos grupos de trabalho em que você atua?

b.4) Qual a sua percepção sobre as mudanças na liderança?

b.5) Que características você percebe na liderança atual (pontos fortes e a melhorar)?

b.6) Você gostaria de fazer algum comentário adicional?

c) Quais são as oportunidades de desenvolvimento da liderança na organização?

c.1) Que características os seus líderes atuais têm?

c.2) Que competências eles demonstram ?

c.3) Como a liderança é exercida pelos seus líderes?

c.4) Quais são as melhores práticas exercidas pelos líderes?

c.5) Que características você gostaria de ver nos seus líderes?

c.6) Como você se sente trabalhando com diversos líderes simultaneamente?

c.7) Você gostaria de fazer algum comentário adicional?

As entrevistas foram iniciadas com a explicação do objetivo da pesquisa, do contrato de confidencialidade das informações e dos informantes, da estrutura das entrevistas, dando-se sempre liberdade para solicitações de esclarecimentos que se fizessem necessários ao longo do processo (Spradley, 1979, 1980).

A análise de dados conceptual indutiva foi empregada neste estudo. Ela inicia-se com a identificação das questões de pesquisa e escolha de uma ou mais amostras, seguindo para o processo de codificação do texto em categorias (redução seletiva), passando para a análise de conteúdo e verificação da confiabilidade das conclusões (Mayring, 2000). A ideia principal desse método é a formulação de um critério de definição, derivado do conhecimento teórico e das questões de pesquisa, os quais determinam os aspectos (características) do material (texto) a ser considerado.

\section{Unidade de análise e sujeitos de pesquisa}

0 ambiente onde a pesquisa foi desenvolvida é uma área de pesquisa e desenvolvimento (P\&D) de uma empresa brasileira líder no seu mercado de atuação. A estrutura é composta por grupos de tecnologia, que na realidade representam o agrupamento de profissionais, dentro de suas especialidades, sendo esses denominados grupos de tecnologia, compondo, por sua vez, um grupo maior chamado pool de recursos. A estratégia que define a alocação de recursos é descrita a seguir:

- Os recursos materiais e pessoas (colaboradores) são alocados por projeto, em equipes temporárias e multifuncionais, via um contrato de execução de atividades;

- Os recursos humanos de $P \& D$ são organizados na forma de um pool único, constituído por grupos de tecnologia;

- Esses grupos fornecem recursos para todos os tipos de projeto (pequenos, médios, grandes e de desenvolvimento tecnológico, cuja classificação faz-se em função do tempo de duração e grau de inovação);

- 0 gerenciamento de recursos ocorre em duas dimensões: recursos $X$ projetos;

- Os recursos são gerenciados através de matrizes de alocação e habilidades. Isso torna possível que um mesmo líder seja responsável por um ou mais projetos, com equipes e duração distintas. 0 mesmo pode ocorre com os liderados, que participam de um ou mais projetos simultaneamente.

Para efeito de coleta de informações, foram considerados basicamente dois aspectos: o tempo do colaborador na organização e o papel atual por ele desempenhado. Do ponto de vista do tempo na organização foi feita uma divisão entre aqueles que têm mais de 10 anos de empresa e aqueles que têm menos de 10 anos. Com relação aos papéis, foi considerado o papel de líder, de liderado e simultaneamente de líder e liderado (trabalhando em outro projeto). A Tabela 1 descreve o perfil da população entrevistada em questão.

A população da área onde se desenvolveu a pesquisa é de 120 colaboradores, sendo que foram

Tabela 1. Perfil dos sujeitos da pesquisa.

\begin{tabular}{lcc}
\hline \multicolumn{3}{c}{ PERFIL DOS ENTREVISTADOS } \\
\hline \multicolumn{1}{c}{ PAPEL } & +10 ANOS & -10 ANOS \\
\hline LÍDER & 4 & - \\
LIDERADO & 4 & 4 \\
LIDER E LIDERADO & - & 4 \\
TOTAL & 8 & 8 \\
\hline
\end{tabular}


entrevistados 16 informantes. 0 tipo de atividade é pesquisa e desenvolvimento de produtos. 0 perfil dos informantes contempla ainda os seguintes dados a respeito da formação acadêmica: seis são pós-graduados, cinco têm curso superior em engenharia e cinco são técnicos, com conhecimento tácito em nível de engenharia. Todos estão em posições semelhantes no plano de carreira da empresa.

\section{Apresentação dos resultados}

Vários temas foram identificados a partir das entrevistas com os informantes. Optou-se por uma categorização desses temas de acordo com as perguntas de pesquisa às quais estavam mais relacionados. Muitos desses temas poderiam ser enquadrados em mais de uma categoria, porém a decisão tomada foi de alocá-los naquela à qual, na opinião dos autores, o grau de pertinência e relevância fosse maior. 0 resultado desse processo de identificação gerou nove temas principais, agrupados em três categorias, como mostrado a seguir.

\subsection{Categoria 1: Como a liderança é exercida na organização na visão de líderes e liderados?}

\section{Tema 1.1 - Competências e qualidades do líder}

Para todos os informantes (líderes e liderados) ouvidos durante as entrevistas fica claro que líderes na sua maioria são feitos e alguns poucos são natos. Essa é uma questão frequentemente encontrada na literatura (Russo et al., 2005). Existe ainda uma percepção de que aqueles que são natos podem ser ainda mais efetivos do que aqueles formados a partir de suas experiências e treinamentos se houver uma dedicação ou preocupação com seu autodesenvolvimento. Ainda nessa visão, líderes em geral, mas em especial os formados, construídos (moldados) ao longo do tempo, devem, acima de tudo, ter vontade de executar o papel de líder. Isso faz com que superem suas dificuldades e que se tornem tão bons como aqueles líderes natos. A partir da pesquisa realizada e considerando o perfil dos entrevistados mostrados na Tabela 1, nota-se que essa visão é compartilhada por líderes, por liderados e por colaboradores que já desempenharam ambos os papéis. As principais características de um líder mais apontadas na pesquisa são mostradas na Tabela 2:

Essas características do líder podem ser analisadas à luz de vários estudos conduzidos por diversos autores e suportadas por diversas teorias. Uma primeira relação a ser analisada é a proposta por Carrilo (2003). Ela estabeleceu uma fórmula de liderança, baseada em termos como confiança, credibilidade e competência:

Liderança $\rightarrow$ Confiança + Credibilidade $x$

Competência $=$ Resultado

A competência, nesse caso, é também traduzida como desenvolvimento organizacional. Toda essa formulação está baseada em três dimensões: a primeira, o desenvolvimento de confiança e credibilidade pessoais; a segunda, a capacitação da organização para o sucesso, via o desenvolvimento de pessoas, processos, estruturas e habilidades para suporte à excelência; $\mathrm{e}$ uma terceira dimensão que consiste na transformação de uma visão em algo concreto, resultados. Para que essa última dimensão seja alcançada, alguns fatores são determinantes, como a geração de insights (como cada um contribui na solução do problema), direção, capacitação (competência de análise), foco e comprometimento.

Um segundo modelo sugerido a ser considerado é o desenvolvido por Galford (2006), onde a liderança confiável pode ser representada por:

(Credibilidade + Confiabilidade + Intimidade) $/$ Auto-orientação $=$ Confiança

Diferentemente de Carrilo (2003), que considera que confiança e credibilidade levam a liderança efetiva (resultado), Galford (2006) parte do princípio de que é a credibilidade que leva a uma liderança confiável, ou seja, a credibilidade é um fator integrante de um conceito mais amplo, o da confiança, que pode ser descrita como uma relação de segurança que se estabelece com alguém quando você está uma posição vulnerável (Hurley, 2006). Nessa perspectiva, a credibilidade é adquirida por capacitação (expertise), pela habilidade em obter a requerida capacitação estando frente a limitações individuais. A confiabilidade está relacionada com a dependência e consistência para com seguidores (senso de conforto gerado), ao

Tabela 2. Principais características de um líder mais apontadas na pesquisa.

\begin{tabular}{cccc}
\hline Comunicação/carisma & Inteligência & Iniciativa & Empatia \\
Inspiração & Visão & Transparência & Objetividade \\
Persuasão/articulação & Proximidade & Autoconfiança & Motivação \\
Gostar de pessoas & Motivador & Benevolência & Respeito \\
Credibilidade & Confiança & Competência & Sociabilidade \\
Ética & Equilíbrio & Perspicácia & Vontade de ser líder \\
\hline
\end{tabular}


passo que a intimidade refere-se a transformar o negócio da organização em um caso pessoal. Para esses autores, o fator que pode afetar negativamente a confiança é a auto-orientação, que nada mais é do que a preocupação (priorização) com interesses próprios quando relacionando-se com outros. Aqueles que são motivados por tarefas ou ganhos pessoais tendem a ser mais auto-orientados do que aqueles motivados por significados (orgulho e reconhecimento) ou que têm prazer com o trabalho. Esse último aspecto é outro exemplo da diferença de enfoque em relação àquele dado por Carrilo (2003), que não considera o fator auto-orientação como prejudicial à liderança (não aparece diretamente na formulação do conceito).

- Tema 1.2 - Vontade de ser líder e gostar de pessoas

Duas características levantadas na pesquisa chamam particularmente a atenção: a vontade de ser líder e não só a habilidade mas, também e fundamentalmente, o fato de o líder gostar de pessoas. $\mathrm{Na}$ visão dos colaboradores da organização, essas características contribuem para um líder ser mais efetivo e competente. Essas características parecem pouco exploradas na literatura, que normalmente é focada em teorias clássicas de liderança e em estudos voltados à análise do líder confiável e com credibilidade. 0 foco é muito grande na competência ou habilidade relacionada mas não contempla questões fundamentais como a vontade de ser líder e o gostar de pessoas. Naturalmente, pessoas podem desenvolver habilidades relacionais e sentirem-se confortáveis em posições de liderança. A característica da vontade de ser líder foi apontada principalmente pelos colaboradores que já foram ou são líderes de equipes atualmente.

Já a característica de gostar de pessoas foi mencionada por todos os entrevistados que desempenharam os papéis de líder e de liderado e por aqueles que hoje atuam como liderados. Não houve menção a essa característica por parte daqueles que atualmente exercem o papel de líder. 0 fato de se gostar das pessoas leva ao entendimento das necessidades dos seguidores. Líderes devem ser sensiveis e estar atentos às necessidades individuais dos seguidores. Isso motiva os empregados e propicia ao líder um melhor direcionamento das tarefas e melhor ambiente de trabalho. Esse aspecto está bem alinhado com a componente consideração individualizada encontrada na liderança transformacional (Bass \& Steidlmeier, 1998), que afirma que seguidores devem ser tratados como indivíduos e respeitados como tal, com seus interesses e motivações individuais. 0 líder adota, nessa situação, uma postura de treinador, orientador e de suporte na geração de oportunidades de crescimento. Kouzes \& Posner (2003) comentam que fluxogramas organizacionais e hierarquia não funcionam, as pessoas têm de ser tratadas como seres humanos, como amigas. 0 reconhecimento deve ser pessoal e individualizado e tem um efeito muito grande sobre as pessoas. Um dos grandes determinantes de uma liderança efetiva é a qualidade do relacionamento com os subordinados. 0 feedback mantém as pessoas engajadas e comprometidas. Líderes efetivos demonstram coragem e convicção, estabelecem bons pensamentos e imagens, encorajam as pessoas, dão prioridade à esperança, constroem vidas saudáveis e atingem níveis superiores de desempenho.

\section{- Tema 1.3 - A importância do líder nato}

É consenso entre os informantes que na organização existem poucos líderes naturais ou natos. A grande maioria é desenvolvida a partir de experiências vividas, treinamento e influências do meio e da família. Em várias entrevistas surgiram menções a competências técnicas, humanas e hierárquicas, classificação essa dada pelos informantes. A primeira diz respeito à formação e conhecimento técnico, a segunda está relacionada com habilidades humanas de relacionamento, empatia e visão, por exemplo. As competências hierárquicas representam a posição do indivíduo, seja no plano de carreira ou na estrutura da organização. Dentro desse contexto, para os informantes, as habilidades humanas são naturais e natas, enquanto que as outras competências são obtidas por aquisição de conhecimento e desenvolvidas por treinamento. No âmbito dessas competências humanas, os fatores que mais influenciam são a família ou pares próximos, o meio, os exemplos, que moldam o caráter. Nessa visão, as demais competências estão ligadas ao esforço, força de vontade, ambição. Vários exemplos de líderes natos foram citados, como os líderes de comunidades e líderes de associações, que mesmo sem as referidas competências técnicas e hierárquicas desenvolvidas assumem posições de liderança via suas competências humanas, altamente destacadas. Um exemplo dessa situação na empresa é o de um operador de linha de montagem que posteriormente passou a ser líder de produção e que por sua habilidade em lidar com pessoas foi expatriado para uma planta da companhia na Europa, onde se tornou gestor da fábrica. Outro exemplo lembrado pelos informantes é o de um contínuo (office boy) que por sua capacidade de relacionamento foi convidado a trabalhar na área de Vendas \& Marketing e que por seus resultados na negociação com clientes passou ao cargo de gestor corporativo de mercado.

0 conceito de liderança, que advém das observações realizadas nesta pesquisa, está muito ligado com a visão da liderança em termos do trabalho adaptativo, conforme sugerido por Heifetz (1994). A totalidade dos informantes afirma que líderes, na sua maioria, são feitos e que alguns poucos são natos. Existe ainda uma percepção de que aqueles que são natos podem ser 
ainda mais efetivos do que os formados a partir de suas experiências e treinamentos, se houver uma dedicação ou preocupação com seu autodesenvolvimento. lsso vem de encontro à definição do que é trabalho adaptativo, que consiste no processo de aprendizado requerido para administrar conflitos de valores pessoais, ou diminuir a distância entre os valores sustentados pelo indivíduo e a realidade que está sendo enfrentada. $\mathrm{Na}$ realidade, as organizações podem ser comparadas a sistemas adaptativos complexos (analogia com sistemas biológicos), cuja sobrevivência a mudanças depende da habilidade de sua autorrenovação. Heifetz (1994) afirma que sistemas procuram (pedem) por equilíbrio. Eles respondem ao stress da mudança para encontrar o ponto de equilíbrio novamente. Uma vez que uma espécie se adapta à mudança, pode ser que não sobreviva (não existe garantia) à próxima que está por vir. Para Heifetz (1994), isso implica em mudanças de valores, crenças, ou comportamento. A palavra chave no trabalho adaptativo é aprendizado, mesmo que a tarefa de desenvolvimento de novos traços seja, por vezes, muito difícil, porque certas características pessoais não são facilmente modificadas (Northouse, 2004).

\subsection{Categoria 2: Quais são as percepções e experiências de líderes e liderados no seu ambiente de trabalho?}

- Tema 2.1 - A coexistência de diferentes estilos de liderança

A estrutura organizacional e a forma de trabalho na área pesquisada levam à identificação de vários tipos de liderança. Dentre essas, as mais destacadas foram a liderança transacional, a transformacional, a pseudotransformacional e o laissez faire. Nesse ponto vale destacar que são todas distribuídas e simultâneas. 0 fato de ser distribuída é explicável e esperado (Hadfield, 2005). Antes de ser um novo tipo de liderança, a liderança distribuída é uma forma diferente de pensar e representar o fenômeno da liderança. 0 processo tem início com a divisão do trabalho (tarefas) dentro das organizações. Essa divisão refere-se a como o trabalho é distribuído e arranjado em tarefas, atividades, estrutura e papéis na organização, como é controlado e executado. Dentro do contexto da liderança distribuída, a questão de como as organizações manifestam a liderança, ou que forma deveria ter essa liderança nas atividades, no ambiente de trabalho, fica em aberto. lsso abre espaço para a manifestação de diversos tipos de lideranças simultâneas distribuídas na organização.

Do ponto de vista do liderado, uma das questões mais significativas passa a ser como conviver com a simultaneidade dos estilos de liderança, ou até com a falta de homogeneidade dessa liderança. Esse aspecto ainda é muito pouco explorado na literatura. Mesmo teorias mais recentes não abordam de forma adequada esse tipo de situação, que é o que realmente acontece na prática, nas organizações atuais. A própria transição de um estilo de liderança para outro, quando mais de um projeto é desenvolvido paralelamente pelo liderado, torna-se interessante e plausivel, necessitando de análises mais aprofundadas. A percepção obtida ao longo da pesquisa é a de que três fatores vêm sendo determinantes para uma convivência mais efetiva e administrável, por parte dos liderados, com esses diversos tipos de liderança, simultaneamente:

1) A tendência de evolução para uma liderança mais democrática, participativa, motivacional, com transparência, rejuvenescida, bem-intencionada e focada em resultados, como sempre o foi;

2) 0 nível de maturidade e autoestima dos entrevistados contribui fortemente para a abertura desse processo na empresa;

3) 0 momento da empresa é muito bom e a própria organização associa a revisão dos processos ao ciclo de vida da organização. 0 momento é propício e coincide com o ponto ascendente da curva do ciclo de vida das organizações. Oportunidades e desafios aos colaboradores estão surgindo no âmbito corporativo e a existência de um plano de carreira estruturado, com avaliações anuais, contribui para a manutenção de um clima de esperança, motivação e reconhecimento.

- Tema 2.2 - Liderança, poder e influência na organização

Como comentado anteriormente, em várias entrevistas surgiram menções às competências técnicas, humanas e hierárquicas, classificação essa dada por todos os informantes, independentemente do papel desempenhado atualmente. A competência técnica diz respeito à formação e conhecimento técnico, enquanto as competências humanas estão relacionadas com habilidades humanas de relacionamento, empatia e visão, por exemplo. As competências hierárquicas representam a posição do indivíduo, seja no plano de carreira ou na estrutura da organização. Associadas a essas competências aparecem menções significativas, na pesquisa, aos poderes de posição e pessoal. Do ponto de vista do poder pessoal é representativa a figura do poder do expertise e do carisma. 0 poder de posição é representado pelo controle sobre as informações e o poder de coerção. Isso ajuda a entender como a convivência e simultaneidade de diversos estilos de liderança acontece na organização. Se de um lado existe a noção positiva do poder pessoal e da geração de um sentimento de amizade e lealdade, resultando em confiança e autoestima elevadas, existe também 
a ciência de que o poder de posição, em algumas situações, é empregado de forma abusiva, o que nas entrevistas ficou caracterizado como gerenciamento pelo terror (ameaças). Existe o sentimento dos informantes, principalmente daqueles que exercem o papel de liderados, de que tais líderes existem, porém representam uma minoria na organização. São os chamados líderes pseudotransformacionais. Esses líderes advogam em seu próprio favor, focam na autoglorificação, distorcem eventos e continuamente dão desculpas. Aspectos morais são percebidos em virtudes como autenticidade, integridade, confiança e credibilidade. Líderes perdem rapidamente a confiança de seus seguidores com a perda de reputação, ou por não falarem a verdade (Bass \& Steidlmeier, 1998). A componente da liderança transformacional que normalmente falta a esse tipo de líder é a consideração individualizada. Para a maioria dos informantes, líderes e liderados, esse tipo de líder não tem vida longa, pois falta sustentação a médio e longo prazo. Uma percepção obtida durante as entrevistas com os informantes é a de que para alguns a estratégia de alianças, empatia e desenvolvimento de redes de relacionamento é muito mais efetiva do que para outros. Esse segundo grupo ainda exerce e faz uso do recurso do apelo do poder de posição de forma mais frequente. Isso acarreta invariavelmente uma grande energia despendida na administração de conflitos.

- Tema 2.3 - A influência da estrutura organizacional no desempenho das equipes (poder do conhecimento e controle sobre as informações)

A influência da estrutura organizacional sobre o desempenho das equipes é muito grande. Essa é uma percepção comum a todos os informantes, independentemente do papel que exercem na organização. Primeiro porque a estrutura organizacional determina a distribuição de tarefas e atividades, fomenta a criação de equipes mais ou menos duradouras (temporárias). A liderança naturalmente torna-se distribuída. Essa divisão refere-se a como o trabalho é distribuído e arranjado em tarefas, atividades, estrutura e papéis na organização, como é controlado e executado. A liderança torna-se distribuída e surgem aspectos positivos. Isso representa o fenômeno decorrente das mudanças nas organizações, para atendimento das necessidades de mercado, via estruturas organizacionais matriciais, saindo do formato vertical e tornando-se cada vez mais horizontais e mais focadas em aspectos humanos e equipes, rompendo com rígidas estruturas hierárquicas. Ou seja, a sobrevivência passa pela adoção de estruturas baseadas nesse formato. Por outro lado, aparecem aspectos negativos decorrentes dessa situação. É inevitável que, com a estrutura organizacional existente na organização em estudo, surjam conflitos relacionados à múltipla alocação de recursos e ao controle sobre eles.

Nessa situação criam-se dois grandes conflitos: para o líder, a defesa de seu projeto e a consecução de seus objetivos e cronogramas de implementação, e, para o liderado, como responder à demanda de dois ou mais projetos concorrentes. Para os líderes, a tendência natural é focar no individualismo, ou seja, o importante para o líder é que o projeto tenha sucesso e que a equipe dedique-se prioritariamente a isso. Para alguns dos informantes o individualismo é muito grande nas pessoas e quando isso acontece no líder, a tendência é ele focar em resultados de curto prazo, com impactos no longo prazo e, por consequência, na excelência. Não existe espaço para coaching. lsso se torna parte da cultura das pessoas.

Essa visão distorcida de que equipes são autogerenciáveis é questionada por Barry (1991). Para ele, esses tipos de equipes são aquelas que necessitam de mais liderança (mais até do que as convencionais). Para Barry (1991), além da liderança baseada em tarefas (definição de projetos, cronogramas, recursos etc.), existe a liderança relativa ao processo de desenvolvimento do grupo (coesão, comunicação efetiva, padrões etc.). Sem uma dessas lideranças, ou com o enfraquecimento de uma delas, surgem os conflitos, seja em relação ao grupo, seja em relação às tarefas por ele desempenhadas. Nessa visão é fundamental a existência de uma autoridade formal. Dai surge um dos grandes mal-entendidos: a confusão de papéis entre líderes e gerentes. Gerentes são designados e aparecem na estrutura organizacional, seja ela formal, duradoura, ou temporária. 0 papel de líder é diferente, embora na própria organização em estudo exista muita confusão em relação a essas definições e a consequente confusão de papéis (líder $\times$ gerente). Muitos gestores sentem-se pouco confortáveis com o papel de líder e confundem ambas as situações. Northouse (2004) define as funções comparativamente a líderes e gerentes, conforme mostrado na Tabela 3.

Tabela 3. Funções de líderes e gerentes, comparativamente.

\begin{tabular}{ll}
\hline \multicolumn{1}{c}{ GERENCIAMENTO } & \multicolumn{1}{c}{ LIDERANÇA } \\
\hline Planejamento: & Estabelecimento de uma direção: \\
- Orçamento & • Criar uma visão \\
- Cronogramas & - Dar uma visão geral (figura) \\
- Alocação de recursos & - Definir estratégias \\
Organização: & Alinhamento de pessoas: \\
- Estrutura de pessoas & - Comunicar objetivos \\
- Alocação de pessoas & - Procurar por comprometimento \\
- Regras e procedimentos & - Construir equipes e coalizões \\
Controle: & Motivação e inspiração: \\
- Solução de problemas & - Inspirar e energizar \\
- Incentivos e soluções criativas & - Dar poder aos subordinados \\
- Ações corretivas & - Satisfazer necessidades \\
\hline Fonte: adaptado de Northouse (2004). &
\end{tabular}


Na visão dos informantes o que faz com que resultados significativos sejam atingidos é a busca por resultados, a questão do cumprimento de prazos, o fato de a organização pensar fora do tradicional e instigar as pessoas, tudo isso alinhado a uma estratégia bem definida de crescimento, além do perfil da mão de obra. 0 que é unânime do ponto de vista de melhoria é a necessidade de quebra do individualismo por projeto, a visão do todo, a aproximação das equipes e a consequente tomada de decisão e priorização de atividades.

A estratégia empregada pela empresa de, gradualmente, não mais centralizar a tomada de decisão, de assegurar a participação dos indivíduos de forma colaborativa na tomada de decisão, e, via de fato, focar na sustentabilidade da organização no longo prazo são características típicas de uma liderança transformacional (Bass, 1997). A motivação dessa liderança passa a ser o envolvimento de seguidores nas mudanças organizacionais, de forma a criar uma produtividade sustentável em longo termo, diferentemente da liderança transacional, mais preocupada com o gerenciamento do dia a dia. 0 compartilhamento da tomada de decisão às vezes torna-se dúbio: permite que efetivamente todo o processo cresça pela divisão de responsabilidades e pelas tomadas de decisão conjuntas (pelo menos algumas das partes são ouvidas), como também cria certo painel de fundo, uma cortina, para postergação ou não de tomadas de decisão relativas a questões como a demanda e priorização de atividades citadas na pesquisa.

0 individualismo e a demora, ou ausência, na tomada de decisões e priorização de ações levantados na pesquisa, acabam influenciando, por vezes negativamente, os fatores construção de equipes e coalizão, a motivação e inspiração - vide Tabela 3 (Northouse, 2004), a qual descreve parte do papel da liderança. Esses são pontos a serem trabalhados internamente, para melhoria do processo de liderança, e que influenciam nos resultados, na percepção dos informantes. Ambos os fatores estão mais relacionados a aspectos comportamentais do que propriamente à estrutura organizacional. A estrutura organizacional fomenta a liderança distribuída, porém não podem ser atribuídas somente a ela as questões mencionadas anteriormente, que são diretamente vinculadas às pessoas.

- Tema 2.4 - A autopercepção como líder verdadeiro

Alguns líderes entrevistados deixam transparecer nos seus comentários a necessidade de, com relativa frequência, tomarem decisões, de realizarem pessoalmente determinadas tarefas. Isso leva a crer que tal comportamento é muito mais individual do que necessariamente estrutural. Essa é uma situação potencialmente complexa, que gera a necessidade de avaliação de novas formas e níveis de delegação, e talvez a consideração de mudanças de estilo de liderança, mais futuramente. Isso tudo sob pena de os gerentes adotarem o papel das chefias, essas, por sua vez, adotarem posturas de supervisores e supervisores transformarem-se em operacionais. Northouse (2004) comenta que um dos tipos de liderança mais conhecidos é baseado no enfoque nas habilidades. Nesse caso, a capacidade do líder está baseada em três características pessoais: as habilidades conceituais, humanas e técnicas. Quanto mais um indivíduo cresce na organização, mais habilidades conceituais e humanas ele tem de apresentar e desenvolver. Nessa mesma situação, menos se exige em termos da habilidade técnica, até pelo envolvimento em outras esferas de atividade na organização, como o estabelecimento de redes de relacionamento e gerenciamento de equipes. A referida sobreposição de papéis gera um vácuo na estrutura, enfraquecendo o papel da gestão, privando a estrutura de uma visão de melhoria futura e de aperfeiçoamentos contínuos, podendo minar, de um modo gradativo, a competitividade da organização.

É destacado o fato de que apenas 50\% dos entrevistados, entre líderes ou liderados, consideram-se, ou têm a percepção de que atuam como líderes, em determinadas situações. Aqueles que se percebem como líderes têm claro para si que isso deriva de traços (características) bem definidos, do conhecimento e experiência adquiridos formalmente e na empresa, dos seus resultados e do seu cargo (posição). Para esse grupo, as habilidades a serem desenvolvidas são a capacidade de convencimento e a gestão de pessoas. Competências técnicas, na opinião dos entrevistados, são mais facilmente adquiridas, em função da organização ser de base tecnológica. Para os outros informantes, que não se percebem como líderes, fica claro que líder para a empresa é o líder formal, responsável pelo projeto, numa explícita demonstração de que para esses colaboradores existe o conflito do poder formal versus o informal (poder pessoal do expertise $\times$ poder de posição). Todos os informantes fizeram menção à posição no plano de carreira como forma de identificação do papel de líder na organização. lsso advém tanto da estrutura organizacional como da definição de papéis e cargos no plano de carreira. Nota-se a confusão entre o que é um papel a ser desempenhado (situacional) e o que significa o cargo ocupado. Retorna nesse ponto a questão de quais são as atribuições dos líderes e quais são as dos gerentes. 


\subsection{Categoria 3: Quais são as oportunidades de desenvolvimento da liderança na organização?}

- Tema 3.1 - Gestão de pessoas e seus impactos no desempenho e atitudes das equipes

Ao mesmo tempo em que se prega o trabalho em equipe, existe também o fomento do individualismo nos processos da organização. Três fatores são determinantes desse tipo de situação: a estrutura organizacional, o plano de carreira e a existência de diferentes tipos de lideranças simultâneas. Esses fatores são determinantes no desempenho dos colaboradores. Eles contribuem de forma individual bem como com sua interação nos resultados das equipes.

A questão da influência da estrutura organizacional já foi abordada anteriormente. A estrutura atual torna possível que um mesmo líder seja responsável por um ou mais projetos, com equipes e duração distintas. 0 mesmo pode ocorre com os liderados, que participam em um ou mais projetos simultaneamente. Na opinião dos informantes, sejam eles líderes ou liderados, o que acaba acontecendo é a geração de dois grandes conflitos: para o líder, a defesa de seu projeto e a consecução de seus objetivos e cronogramas de implementação, e, para o liderado, a questão de como responder à demanda de dois ou mais projetos concorrentes. Para os líderes, a tendência natural é focar no individualismo, ou seja, o importante para o líder é que o projeto tenha sucesso e que a equipe dedique-se prioritariamente a isso. 0 reforço a esse comportamento é dado pelo plano de carreira e pela cultura da empresa, que reconhece principalmente os resultados e habilidades técnicas individuais. Isso parece acentuar o aspecto (percepção obtida) de que o colaborador só cresce e é reconhecido formal e informalmente na área e se for muito competente tecnicamente, mesmo que para a sua função atual isso, em teoria, não deva ser determinante. Isso estimula a competição e fomenta a troca ou confusão de papéis entre líder e liderados. 0 primeiro (líder) vai ser cobrado pelo histórico técnico devido à cultura existente na empresa, de base tecnológica, levando a maior valorização do poder do conhecimento e da informação (Gallon \& Ensslin, 2008).

Do ponto de vista do liderado, uma das questões mais significativas passa a ser como conviver com a simultaneidade dos estilos de liderança, ou até com a falta de homogeneidade dessas lideranças. Apesar da existência desses conflitos, existe a percepção dos informantes de que a organização está no caminho certo e de que houve uma evolução na liderança através dos tempos, principalmente na última década. Essa última data coincide com o processo de reengenharia ao qual a organização foi submetida.

- Tema 3.2 - Características do líder a serem desenvolvidas e oportunidades de benchmark

Foram levantadas ao longo deste trabalho algumas das melhores práticas e oportunidades de desenvolvimento de características dos líderes. As principais características a serem melhor desenvolvidas estão relacionadas na Tabela 4:

É possível dividir as características citadas em dois grupos: o primeiro relacionando aspectos de preservação e construção de relacionamentos, que são constituídos pela empatia, interação com pessoas, integração de pessoas e a busca pelo coletivismo como uma alternativa ao individualismo vigente. Um segundo grupo identificado é composto pela comunicação, o feedback, o coaching, ou seja, desenvolvimento de pessoas e, em algumas situações, da flexibilidade. Esses elementos são típicos e representativos da liderança transformacional, mais propriamente das componentes do carisma ou influência idealizada, essa podendo ser atribuída ou comportamental (ela proporciona altos padrões de emulação, gerando visão e confiança), e da componente consideração individualizada, que consiste no tratamento dos seguidores como indivíduos, via seu treinamento, desenvolvimento e orientação na busca de seu crescimento.

No que diz respeito às melhores práticas dos líderes pode-se citar o conteúdo da Tabela 5. A mensagem que resume o conjunto de melhores práticas mencionado é a busca por resultados, cumprimento de prazos, altos níveis de organização e disponibilidade de recursos humanos e materiais, a atitude de pensar fora do tradicional e com isso instigar as pessoas, e uma estratégia de negócio bem definida, atrelada a uma clara visão de futuro. Nesse sentido surge uma menção à liderança transformacional, aqui representada pelas componentes da motivação inspiracional, que provê desafios e engajamento dos seguidores para com objetivos compartilhados e a estimulação intelectual,

Tabela 4. Principais características dos líderes a serem melhor desenvolvidas.

\begin{tabular}{cccc}
\hline Comunicação & Feedback & Empatia & Coletivismo \\
\hline Coaching & Flexibilidade & Interação & Integração \\
\hline
\end{tabular}

Tabela 5. Melhores práticas dos líderes da organização pesquisada.

\begin{tabular}{cccc}
\hline Responsabilidade & Avaliação de desempenho & Tenacidade & Equilíbrio emocional \\
\hline Visão de futuro & Delegação & Segurança & Organização \\
\hline
\end{tabular}


que fomenta a formulação de uma visão, da análise crítica e da avaliação de situações, implementação de padrões e geração de soluções criativas.

Percebe-se também a representação da liderança transacional, principalmente no que diz respeito à recompensa contingencial - vide citação da avaliação de desempenho por todos os entrevistados que exercem o papel de liderados. Nesse caso, líderes devem indicar, ou então consultar seus seguidores, sobre o que tem de ser feito em troca de recompensas implícitas ou explícitas.

\section{Considerações finais}

A análise de como a liderança é exercida na organização (categoria 1 - item 5.1) e das percepções e experiências dos informantes no seu ambiente de trabalho (categoria 2 - item 5.2) refletem um anseio por parte de líderes e liderados por uma liderança cada vez mais transformacional, ao invés de transacional. A liderança transformacional é composta pelos componentes do carisma ou influência idealizada, motivação inspiracional, estimulação intelectual e consideração individualizada (Bass \& Steidlmeier, 1998). A influência idealizada (carisma) é percebida através da capacidade de o líder estabelecer relações e influenciar a organização, na liderança pelo exemplo, na construção do orgulho e senso de propósito da equipe e na habilidade de comunicação. As características de estímulo a mudanças e melhorias, empowerment, desenvolvimento da agilidade das equipes, inspiração para atingir resultados extraordinários e a difusão de uma visão e direção são representativas da componente motivação inspiracional. A tomada de decisão, o foco nas soluções, via a aceitação de erros e experimentações, são representativos da componente estimulação intelectual. A consideração individualizada pode ser encontrada no interesse com o bem-estar dos empregados, através do tratamento das pessoas como seres humanos, na identificação e atendimento das necessidades individuais e do grupo e no desenvolvimento de pessoas, seu treinamento e capacitação. A participação das equipes no planejamento de atividades e definição de metas, o incentivo à participação nos processos decisórios, a contínua geração de oportunidades de crescimento pessoal e a exposição a desafios em um mundo globalizado têm sido determinantes para a transição de uma liderança transacional para uma liderança transformacional. Por esse motivo as organizações têm de estar estruturalmente preparadas para os desafios contínuos da mudança (pessoas, recursos e estrutura organizacional). Essa preparação não ocorre da noite para o dia, deve ser levada a cabo continuamente. De acordo com
Bass \& Steidlmeier (1998), o melhor enfoque é uma liderança predominantemente transformacional e autêntica, combinada com elementos da liderança transacional. A liderança transacional complementa a liderança transformacional mas não a substitui. Ela é empregada por líderes transformacionais para aumentar o poder de negociação e trazer benefícios coletivos para o grupo de trabalho. Nessa situação, a componente da liderança transacional a ser preservada é a recompensa contingencial.

As oportunidades de desenvolvimento da liderança na organização avaliada (categoria 3 - item 5.3) estão alinhadas com tendências da liderança encontradas na literatura, como os trabalhos de Martin (2007) e Ardichvili \& Kuchinke (2002). Ambos os estudos estão relacionados com pesquisas globais sobre o futuro da liderança, nos continentes americano, europeu e asiático. Martin (2007) identificou que a liderança está mudando, focando-se mais em aspectos como colaboração, flexibilidade, abrangência e coletivismo, fugindo do controle explícito representado pelos componentes do gerenciamento ativo e passivo por exceção, característicos da liderança transacional. A grande tarefa dos líderes passa a ser o foco na energia despendida para criação e melhoria de ambientes de trabalho e no fomento da gestão participativa. Isso é representativo da componente motivação inspiracional da liderança transformacional. A liderança torna-se ou passa a ser encarada como um processo coletivo, mudando o enfoque individual, ou seja, com o poder e a influência emanando da posição. Para Ardichvili \& Kuchinke (2002), altos níveis de individualismo estão associados ao foco no eu, com ênfase em iniciativas individuais e tomadas de decisão ao invés do foco no grupo, em uma clara alusão à identidade baseada no indivíduo e não no coletivo.

Acredita-se que este estudo possa contribuiu para o aumento da base de conhecimento em liderança, particularmente no que se refere à sua aplicação prática em uma empresa líder mundial de mercado a partir do Brasil. Os resultados aqui obtidos são específicos da organização avaliada e representam um anseio, por parte de líderes e liderados, por uma mudança no estilo de liderança. Embora não seja possível afirmar que o foco no coletivismo seja melhor do que no individualismo da liderança (ou vice-versa), é esperado que essa mudança seja benéfica para a organização e reflita-se em melhores condições de trabalho, satisfação dos colaboradores e melhor desempenho dos indivíduos e da empresa. De acordo com Campos (2008), o novo paradigma para as organizações pressupõe a troca, a participação, a construção de redes de relações e a aprendizagem individual e coletiva, favorecendo a conexão efetiva e intelectual entre as pessoas e tornando o trabalho um veículo de satisfação e realização pessoal e profissional. 


\section{Referências}

Ancona, D. (2005). Leadership in an Age of Uncertainty. Cambridge: Research Brief, MIT Leadership Center.

Ardichvili, A., \& Kuchinke, P. (2002). Leadership styles and cultural values among managers and subordinates: a comparative studies of four countries of the former Soviet Union, Germany and the US. HRDI.

Barry, D. (1991). Managing the Bossless Team: Lessons in Distributed Leadership. Organizational Dynamics, 21, 31-47. http://dx.doi.org/10.1016/0090-2616(91)90081-J

Bass, B. M. (1997). The Ethics of Transformational Leadership. Academy of Leadership Press.

Bass, B. M., \& Steidlmeier, P. (1998). Ethics, Character, and Authentic Transformational Leadership. Binghamton: Center for Leadership Studies, School of Management, Binghamton University.

Campos, M. V. K. (2008). 0 papel da liderança na motivação das pessoas em ambientes organizacionais. Revista de Gestão Pública, 2(2).

Carrilo, A. C. (2003). Leadership Formula: Trust + Credibility $\mathrm{X}$ Competence $=$ Results. ASSE Middle East Petroleum Conference Keynote.

Galford, R. (2006). The Trusted Leader. Management Forum Series.

Gallon, A. V., \& Ensslin, S. R. (2008). Potencial de liderança criativa em equipes de trabalho de empresas de base tecnológica incubadas. Revista de Administração e Inovação, 5(1), 20-35.

Hadfield, M. (2005). Middle Leaders and Nature of Distributed Leadership in Networks. In American Educational Research Association (AERA) Conference, Montreal.

Heifetz, R. A. (1994). Leadership without easy answers. Cambridge: Harvard University Press.
Hurley, R. F. (2006). The Decision to Trust. Harvard Business Review. PMid:16967620.

Kouzes, J., \& Posner, B. (1987). The leadership challenge: How to get extraordinary things done in organizations. Jossey-Bass Publishers.

Kouzes, J., \& Posner, B. (2003). The Leadership Challenge. National College for School Leadership.

Martin, A. (2007). The Changing Nature of Leadership. Center for Creative Leadership.

Mayring, P. (2000). Qualitative Content Analysis. Qualitative Social Research Forum, 1(2).

Menegasso, M. E., \& Salm, J. F. (2005). Transformação organizacional: proposta de modelo para empresas públicas. Revista de Ciências da Administração, 7(14), 1-24.

Morgan, G. (1980). Paradigms, Metaphors, and Puzzle Solving in Organization Theory. Cornell University.

Northouse, P. G. (2004). Leadership: Theory and Practice. Thousand Oaks: Sage Publications. PMid:15376285.

Politis, J. D. (2003). The effect of Managerial Power and Relational Trust on the Skills and Traits of Knowledge Acquisition: Evidence from the United Arab Emirates. Academic Conferences limited.

Russo, R. F. S. M., Ruiz, J. M., \& Cunha, R. P. (2005). Liderança e influência nas fases de projeto. Revista Produção, 15(3), 362-375. http://dx.doi.org/10.1590/ S0103-65132005000300007

Spradley, J. P. (1979). The Ethnographic Interview. Macalester College, Wadsworth Group. Thomson Learning.

Spradley, J. P. (1980). Participant Observation. Orlando: Harcourt Brace Jovanovich Inc.

Stone, G. A., \& Patterson, K. (2005). The History of Leadership Focus. School of Leadership Studies, Regent University.

Yukl, G. (2002). Leadership in Organizations. Prentice Hall. PMid:11820775.

\title{
Profile and leadership tendencies of a Brazilian worldwide leading company
}

\begin{abstract}
The purpose of this work is to contribute to the understanding of how leadership currently occurs in a Brazilian company, in a scenario marked by vast uncertainties. The study includes qualitative research oriented by the interpretative paradigm. It describes and interprets the leadership phenomena with data collected from participant interviews. The survey was conducted in a research and development area of a leading Brazilian company. Transaction and transformational leadership styles were considered in the characterization. Aspects related to the evolutional trend of this leadership and its situation in a global scenario are also addressed.
\end{abstract}

Keywords

Leadership style. Organizational behavior. Organizational structure. 